\title{
EFFECTIVENESS OF MAGNESIUM SULFATE WITH GLYCERINE VERSUS COLD COMPRESS ON PATIENTS WITH PERIPHERAL INTRAVENOUS CANNULA INDUCED PHLEBITIS
}

\author{
ALWIN T VARGHESE, MOLY KT* \\ Department of Medical Surgical Nursing, Amrita College of Nursing, Amrita Vishwa Vidyapeetham, Kochi, Kerala, India. \\ Email: ktmoly@aims.amrita.edu
}

Received: 28 March 2018, Revised and Accepted: 18 June 2018

\begin{abstract}
Objective: The objective of the study was to determine the effectiveness of magnesium sulfate with glycerine versus cold compress on patients with a peripheral intravenous cannula (PIVC) induced phlebitis.

Methods: A quasi-experimental pre-test post-test study on 60 subjects, 30 in each group, with interventions magnesium sulfate with glycerine application to one group and cold compress to another group of patients with PIVC induced phlebitis was done in a tertiary care hospital, Kerala. Purposive sampling with random allocation of subjects to each group was done. A standardized visual infusion phlebitis (VIP) scale was used to assess the severity of PIVC induced phlebitis.

Results: Both magnesium sulfate with glycerine ( $\left.M D=2.1, t_{29}=16.16, p<0.001\right)$ and cold compress $\left(M D=1.6, t_{29}=17.59, p<0.001\right)$ were found to be effective in reducing the PIVC induced phlebitis. The difference in post-interventional VIP scores between application of magnesium sulfate with glycerine and cold compress was found to be statistically significant $\left(\mathrm{F}_{(1,57)}=5.362 *, \mathrm{p}<0.05\right)$. The mean post-interventional VIP scores of magnesium sulfate with glycerine application (0.059) was less than the cold compress $(0.274)$. The study concluded that magnesium sulfate with glycerine application was more effective than cold compress for treating PIVC induced phlebitis.
\end{abstract}

Conclusion: The study highlights the significance of exploring the foremost effective intervention out of the many good practices currently in use in the prevention and management of phlebitis.

Keywords: Peripheral intravenous cannula, Phlebitis, Cold compress, Magnesium sulfate with glycerine, Visual infusion phlebitis score.

(C) 2018 The Authors. Published by Innovare Academic Sciences Pvt Ltd. This is an open access article under the CC BY license (http://creativecommons. org/licenses/by/4. 0/) DOI: http://dx.doi.org/10.22159/ajpcr.2018.v11i10.26289

\section{INTRODUCTION}

A nosocomial infection is specifically one that was not present or incubating before the patient being admitted to the hospital but occurred within $72 \mathrm{~h}$ after admittance to the hospital [1]. The use of intravenous (IV) devices is an integral part of patient care in hospitals, which may probably lead to complications, of which the most frequent is phlebitis, which means inflammation of the vein. In modern medical practice, up to $80 \%$ of hospitalized patients received IV therapy at some point during their admission [2-4].

Patients acquiring chemotherapy for cancer are at high risk for venous thromboembolism [5]. Thrombophlebitis accounts for considerable iatrogenic morbidity [6]. The reported incidence of phlebitis ranges from $10 \%$ to $90 \%$ of peripheral IV catheterization [7]. If left untreated, it can lead to infection or thrombus formation. Hence, it is essential for the nurses to treat the patients with phlebitis promptly with costeffective thus preventing complications related to phlebitis [8].

Phlebitis can be categorized as chemical, mechanical or bacterial; however, two or more of the kind of irritation often occur simultaneously. Infusion Nurses Society has identified specific standards for assessing phlebitis [9].

Phlebitis is graded according to the most severe presenting indication.

Grade Clinical criteria

0 No clinical symptoms

1 Erythema at access site with or without pain

2 Pain at access site, erythema, edema, or both
3 Pain at the access site, erythema, edema or both, streak formation, and palpable venous cord (1 inch or shorter)

4 Pain at access site with erythema, streak formation, palpable venous cord (linger than 1 Inch), and purulent drainage [10].

Increased incidence rates of infusion-related phlebitis were associated with male sex, small catheter size (20 gauge), insertion at the sites of forearm, IV drug administration, and blood product transfusions [11].

Treatment consists of discontinuing IV line, applying a cold compress first to decrease the flow of blood and increase platelet aggregation followed by a warm compress; elevating the extremity and restarting the line in the opposite extremity [12]. Common medications used for treating phlebitis were magnesium sulfate, glycerin, hot and cold applications, and heparin creams, of which magnesium sulfate with glycerin and cold compress is the two interventions commonly used. Even though these therapies are very commonly practiced independently or in combination, studies comparing their effectiveness are found to be minimal. Choosing the best intervention is still confusing and debatable for the practicing nurse. Hence, the study was undertaken.

\section{METHODS}

Quasi-experimental pre-test - post-test research design was used. Patients with peripheral IV cannula (PIVC) induced phlebitis admitted in orthopedics, surgical medical, gastro, pulmonology, and cardiology wards of a tertiary care Hospital, Kerala, India, were selected. Purposive sampling with random allocation to Groups A and B was done. A total of 60 subjects, 30 in each group, who fulfilled the selection criteria, i.e., 
who developed phlebitis during the present hospitalization, who were conscious and able to report pain and in the age group of 18-60 years were only included.

\section{Ethical clearance}

Ethical Clearance was obtained from Thesis Review Committee of the institution. Written consent was taken from each subject before data collection.

\section{Data collection instruments}

Tool I: A structured questionnaire on demographic and clinical data.

\section{Demographic data}

It included eight questions on patient's age, gender, educational status, monthly income, smoking, alcoholism, and tobacco chewing as reported by the subjects.

\section{Clinical data}

It included 11 questions on diagnosis, frequency of IV cannula flushing, appearance of intravenous (IV) cannulation dressing, presence of coexisting diseases, diagnosis, types of IV infusion, site of IV, number of prick during the IV cannulation procedure, size of PIVC, types of medication infused, period of hospital stay, and duration of PIVC as taken from the clinical records.

Tool II: Visual infusion phlebitis (VIP) scale

A standardized tool developed by Ms. Andrew Jackson to assess the severity of phlebitis. Minimum score of the scale is zero (no phlebitis) and maximum five (severe phlebitis). The total score is interpreted as mild $(<2)$, moderate $(2-3)$, and severe $(>3)$. The content validity of the tool was 0.94 and reliability was 0.85 .

\section{Interventions}

Group A: After the initial assessment, the cannula was removed from the site if it was present and the area was cleaned with normal saline. Then, a pre-prepared mixture of $30 \mathrm{mg}$ of magnesium sulfate and $50 \mathrm{ml}$ of glycerine was soaked in gauze (2" $\times 2$ ") and applied by the researcher at the site of PIVC induced phlebitis, 3 times a day for 3 consecutive days. Approximately $15 \mathrm{~g}$ was used for single dressing. Before the next application, the dressing was removed. The time taken for the dressing was $10 \mathrm{~min}$

Group B: After the initial assessment, the cannula was removed from the site if it was present and the area was cleaned with normal saline. Then, gauze $\left(2\right.$ " $\times 2$ ") was soaked in cold water of a temperature $<15^{\circ} \mathrm{C}$ and applied at the phlebitis site for a period of $20 \mathrm{~min}, 3$ times a day for 3 consecutive days. The cold water was stored in the refrigerator in the respective wards 1 day before the dressing. The cold water was taken from the refrigerator just before the dressing and applied within $1 \mathrm{~min}$. After 20 min of application, the gauze for cold compress was removed from the phlebitis site.

The post-test was conducted for both the Groups A and B using the VIP scale after 3 days of intervention.

\section{RESULTS}

\section{Section A - demographic and clinical data}

Around half of the subjects in Group A, 13 (43.4\%) belong to the age group of 33-46 years and in Group B, 14 (46.7\%) belong to the age group of 47-60 years. The other demographic variables were approximately equal in both the groups.

IV cannula was inserted within two pricks in both the groups: Group A $18(60 \%)$ and Group B 25 (83.4\%). The size of the cannula used was $22 \mathrm{G}$ in majority, i.e., 20 (66.7\%) in Group A and 22 (73.3\%) in Group B. Metacarpal vein was the most commonly used vein for cannula insertion in both the groups: Group A 12 (40.5\%) and Group B 17 (56.7\%), respectively.
Section B: Comparison of pre- and post-interventional VIP scores of subjects with PIVC induced phlebitis in Group A and Group B Fig. 1 shows that $25(83.3 \%)$ subjects with moderate severity of phlebitis and $5(16.7 \%)$ with mild phlebitis returned to either normal status $27(90 \%)$ or mild phlebitis $3(10 \%)$ in Group A after magnesium sulfate with glycerine application.

Fig. 2 shows that $22(73.3 \%)$ subjects with moderate phlebitis and $8(26.7 \%)$ with mild phlebitis returned to either normal status $23(76.7 \%)$ or mild phlebitis $7(23.3 \%)$ in Group B after cold compress application.

Fig. 3 depicts that the pre mean VIP score (2.2) of Group A was reduced to 0.1 after the application of magnesium sulfate with glycerine. The pre mean VIP score (1.83) of Group B was reduced to 0.23 after the application of cold compress.

From this table, it is clear that the calculated $F$ (1.57) value (5.362 and $10.365)$ was greater than the table value (4.154). It means that there was a significant difference between effectiveness of interventions in Groups A and B (Tables 1-3).

\section{DISCUSSION}

The main objective of the study was to compare the effectiveness of magnesium sulfate with glycerine versus cold compress on PIVC induced phlebitis.

The findings of this study have clearly shown that magnesium sulfate with glycerine was more effective than cold compress $F_{(1,57)}$ value

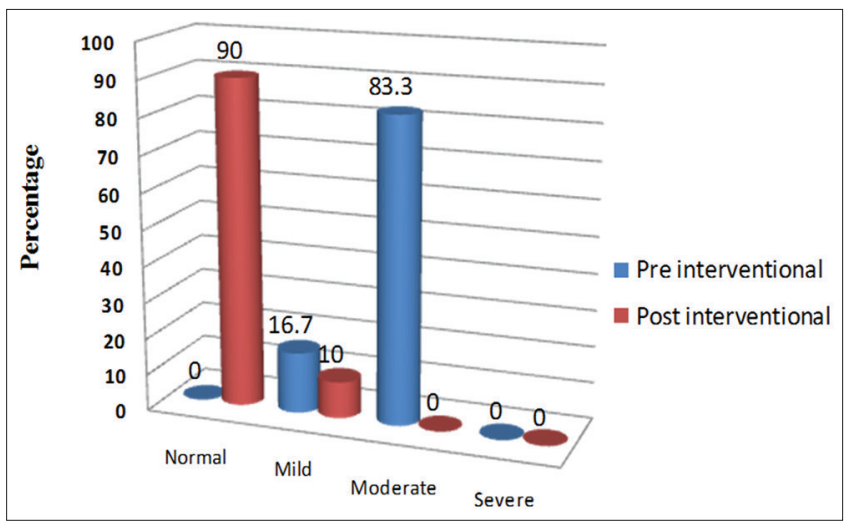

Fig. 1: Distribution of subjects based on the severity of phlebitis pre- and post-interventional - in Group $A$

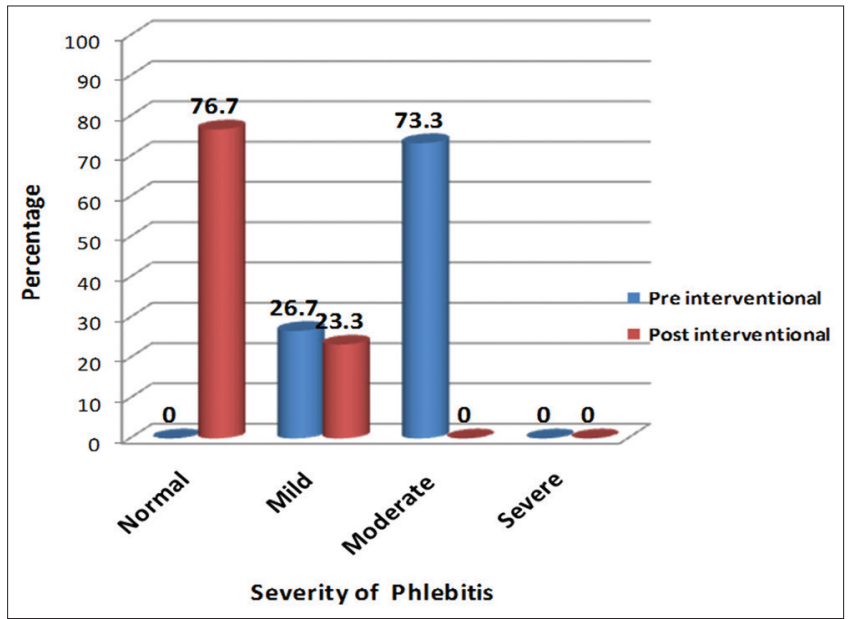

Fig. 2: Distribution of subjects based on severity of phlebitis - preand post-intervention - in Group B 


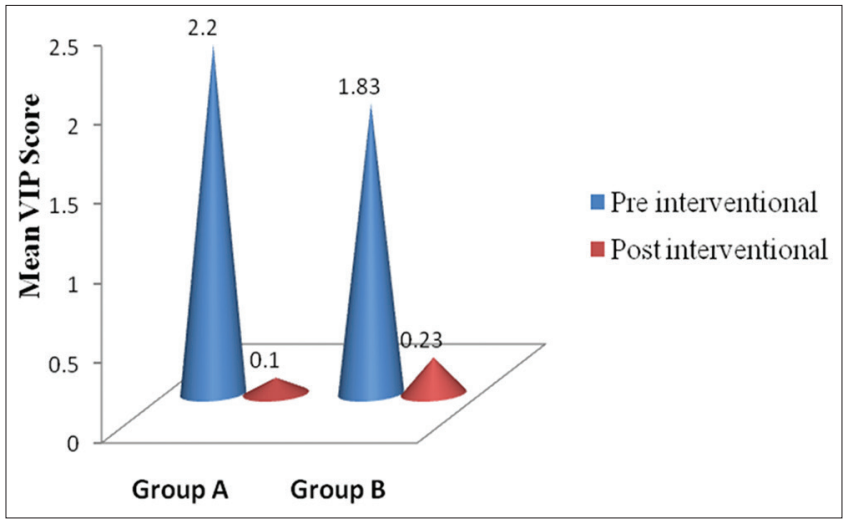

Fig. 3: Mean pre- and post-interventional visual infusion phlebitis scores of Groups A and B

Table 1: Distribution of subjects based on demographic variables (Groups $A$ and $B)(n=60)$

\begin{tabular}{|c|c|c|}
\hline \multirow{2}{*}{$\begin{array}{l}\text { Demographic } \\
\text { characteristics }\end{array}$} & \multicolumn{2}{|l|}{ Frequency (\%) } \\
\hline & Group A $(n=30)$ & Group B $(n=30)$ \\
\hline \multicolumn{3}{|l|}{ Age (in years) } \\
\hline $18-32$ & $10(33.0)$ & $9(30.0)$ \\
\hline $33-46$ & $13(43.4)$ & 7 (23.3) \\
\hline $47-60$ & $7(23.3)$ & $14(46.7)$ \\
\hline \multicolumn{3}{|l|}{ Gender } \\
\hline Male & $19(63.3)$ & $20(66.7)$ \\
\hline Female & $11(36.7)$ & $10(33.3)$ \\
\hline \multicolumn{3}{|c|}{ Occupational status } \\
\hline Unemployed & $14(46.7)$ & $12(40.0)$ \\
\hline Employed & $16(53.3)$ & $18(60.0)$ \\
\hline \multicolumn{3}{|c|}{ Use of vibrating devices } \\
\hline Yes & $9(30.0)$ & $6(20.0)$ \\
\hline No & $21(70.0)$ & $24(80.0)$ \\
\hline \multicolumn{3}{|l|}{ Use of alcohol } \\
\hline Yes & $12(40.0)$ & $11(36.7)$ \\
\hline No & $18(60.0)$ & $19(63.3)$ \\
\hline \multicolumn{3}{|c|}{ Habit of chewing tobacco } \\
\hline Yes & $4(13.3)$ & $2(6.7)$ \\
\hline No & $26(86.7)$ & $28(93.3)$ \\
\hline \multicolumn{3}{|l|}{ Smoking status } \\
\hline Yes & $4(13.3)$ & $2(6.7)$ \\
\hline No & $26(86.7)$ & $28(93.3)$ \\
\hline
\end{tabular}

(5.362 and 10.36, $\mathrm{p}<0.05$ ) in reducing PIVC induced phlebitis, although both the interventions (magnesium sulfate with glycerine as well as cold compress) were found to be effective.

A similar comparative, three groups pre-test, post-test, and quasiexperimental study were conducted by Saini and Paul (2011) to study the effectiveness of cold application, magnesium sulfate application and also heparinoid application on superficial thrombophlebitis on 45 patients in Choithram Hospital and Research Centre, Indore. The cold application was given to experimental Group C, for a period of 20 min, experimental group $(\mathrm{H})$ was intervened by gentle massage with Thrombophob ointment and similarly in experimental group (M), magnesium sulfate dressing was done by dipping the gauze in the magnesium sulfate glycerine solution and applying it on phlebitis area. All applications were given 3 times a day for 3 days. The finding of the study indicated that the computed " $\mathrm{t}$ " value of cold application group ( $\left(\mathrm{t}\right.$ " $\left.{ }_{14}=14.33\right)$, heparinoid application group ( $\mathrm{t}$ ' $\left.{ }_{14}=11.90\right)$, and magnesium sulfate application group ( $\left.^{\prime}{ }_{14}=20.82\right)$ were statistically significant at $\mathrm{p}<0.001$, which suggested that all three interventions were effective in reducing the signs and symptoms of superficial thrombophlebitis. The computed " $F$ " ratio of all the three groups $\left({ }^{\prime} F_{2,42}^{\prime}=10.10, p<0.001\right)$ showed that the three applications differ significantly from each other. The mean difference of magnesium
Table 2: Distribution of subjects based on clinical variables (Groups $A$ and $B)(n=60)$

\begin{tabular}{lll}
\hline Clinical variable & Frequency (\%) \\
\cline { 2 - 3 } & Group A (n=30) & Group B (n=30) \\
\hline $\begin{array}{l}\text { Type of medication } \\
\text { administered }\end{array}$ & \\
$\quad$ Crystalloids & $24(80.0)$ & $25(83.3)$ \\
Colloids & $0(0.0)$ & $0(0.0)$ \\
Both & $6(20.0)$ & $5(16.7)$ \\
Number of prick during IV & & \\
cannulation & & \\
1 & $13(43.4)$ & $10(33.4)$ \\
2 & $12(40.0)$ & $15(50.0)$ \\
3 & $4(13.3)$ & $4(13.3)$ \\
$>3$ & $1(3.3)$ & $1(3.3)$ \\
Size of peripheral cannula & & \\
inserted & & \\
24G & $1(3.3)$ & $0(0.0)$ \\
22G & $20(66.7)$ & $22(73.3)$ \\
20G & $8(26.7)$ & $6(20.0)$ \\
18G & $1(3.3)$ & $2(6.7)$ \\
Presence of peripheral IV & & \\
cannula (in h) & & \\
$<24$ & $2(6.7)$ & $7(23.3)$ \\
24-36 & $15(50.0)$ & $8(26.7)$ \\
36-48 & $3(10.0)$ & $7(23.3)$ \\
$>48$ & $10(33.3)$ & $8(26.7)$ \\
Site of peripheral IV cannula & & \\
insertion & & $2(6.7)$ \\
Cephalic vein & $3(10.0)$ & $3(10.0)$ \\
Cubital vein & $4(13.3)$ & $4(13.3)$ \\
Basilic vein & $6(20.0)$ & $3(10.0)$ \\
Median vein & $5(16.7)$ & $17(56.7)$ \\
Metacarpal vein & $12(40.0)$ & $1(3.3)$ \\
Digital vein & $0(0.0)$ & \\
\hline
\end{tabular}

Table 3: Analysis of covariance of VIP scores in Groups A and $B(n=60)$

\begin{tabular}{llllll}
\hline Source & Df & $\begin{array}{l}\text { Sum of } \\
\text { square }\end{array}$ & $\begin{array}{l}\text { Mean } \\
\text { squares }\end{array}$ & F value & p value \\
\hline Between groups & 1 & 1.241 & 1.241 & $10.365^{*}$ & 0.002 \\
& 1 & 0.642 & 0.642 & & 0.024 \\
Within groups & 57 & 6.826 & 0.120 & $5.362^{*}$ & \\
Total & 59 & 8.333 & & & \\
\hline
\end{tabular}

$\mathrm{F}_{(1,57)}=4.154, \mathrm{p}<0.05$, *Significant. VIP: Visual infusion phlebitis

sulfate group (18.34) was higher than the cold application (13.33) and heparinoid application (12.8) group. This indicated that magnesium sulfate application was most effective in reducing the signs and symptoms of superficial thrombophlebitis [13].

In yet another study conducted by Yambem et al. at Belgam, it was found that application of glycerin with magnesium sulfate was more effective than heparin - benzyl nicotinate (Thrombophob) ointment in the management of cannula induced thrombophlebitis [14].

The study findings have reinforced the effectiveness of magnesium sulfate with glycerine in reducing PIVC induced phlebitis than cold compress. However, more researches in homogenous groups are required to strengthen similar cost-effective interventions to alleviate the discomfort and agony of patients with phlebitis.

\section{CONCLUSION}

The study highlights the significance of exploring the foremost effective intervention out of the many good practices currently in use 
in the prevention and management of phlebitis. The impact of the best quality intervention, although seems to be very simple, go a long way in preventing the occurrence of nosocomial infections in patients, reducing the length of hospital stay and financial burden.

\section{AUTHORS' CONTRIBUTIONS}

The author has contributed substantially toward the study starting from the conception of the problem, its design, data collection, analysis, interpretation of data, and write up as the guide.

\section{CONFLICTS OF INTEREST}

Authors declare that there are no conflicts of interest.

\section{REFERENCES}

1. Webster's New World Medical Dictionary. Nosocomial. $3^{\text {rd }}$ ed. Baltimore: Williams and Wilkins; 2008. p. 1789.

2. Waitt C, Waitt P, Pirmohamed M. Intravenous Therapy; 2004. Available from: http://www.pmj.bmj.com/content/80/939/1.full. [Last cited on 2011 Nov 13].

3. Potter and Perry. Fundamentals of Nursing. $6^{\text {th }}$ ed. New Delhi (India): Elsevier publication; 2005. P. 779-80, 1253, 1554.

4. Chhabra P, Saraf S, Ali R, Rawat H, Mittal G, Bhatnagar A, et al. Development and evaluation of freezing resistant intravenous fluid. Int J Pharm Pharm Sci 2014;6:490-6.

5. Gupta M, Dahiya J, Marwaha RK, Dureja H. Therapies in cancer treatment: An overview Int J Pharm Pharm Sci 2015;7:1-9.
6. Zhao Y, Hao Y, Zhang H, Shi J, Xie Y. Clinical re-evaluation of effects of different treatments to prevent from phlebitis induced by Chansu injection. Zhongguo 2011;36:2803-6.

7. O'Grady NP, Alexander M, Burns LA, Dellinger EP, Garland J, Heard SO, et al. Guidelines for the prevention of intravascular catheterrelated infections. Clin Infect Dis 2011;52:e162-93.

8. Smeltzer SC, Bare BG, Hinlke JL, Cheever KH. Brunner and Suddarth's Text book of Medical Surgical Nursing. Vol. 1. 12 $2^{\text {th }}$ ed. New Delhi (India): Wolters Kluwer; 2010. p. 308-9.

9. Infusion Nurses Society. Infusion nursing standards of practice. J Infus Nurs 2011;34:S65

10. Infusion Nurses Society. Infusion nursing standards of practice. J Infus Nurs 2006;29:S1-92.

11. Singh R, Bhandary S, Pun KD. Peripheral intravenous catheter related phlebitis and its contributing factors among adult population at $\mathrm{KU}$ teaching hospital. Kathmandu Univ Med J (KUMJ) 2008;6:443-7.

12. Hinkle JL, Cheever KH. Brunner and Suddarth's text book of Medical-Surgical Nursing. Vol. 1. $13^{\text {th }}$ ed. New Delhi: Wolters Kluwer publication; 2015. p. 283.

13. Saini B, Paul P. Effectiveness of cold application, heparinoid application and magnesium sulphate application on superficial thrombophlebitis among patients. Ind J N Stud 2011;2:4-10.

14. Yambem M, Madhale M, Bagi D. A comparative study to assess the effectiveness of glycerin with magnesium sulphate versus heparin benzyl nicotinate (Thrombophob) ointment on management of thrombo phlebitis among patients admitted in intensive care units (ICU) of selected hospital in Belgaum, Karnataka. Int J Sci Res 2013;4:1458-61. 